生物化学

\title{
日本血吸虫精氨酸转氨酶及乌氨酸 转氨酶的研究
}

\author{
陶义訓 黄左銭 馮 正 杭省嘉 \\ (中国医学科学院寄生虫病研究所)
}

在日本血吸虫的转氨酶研究中, 我们发 现当以精氨酸为底物时, 有很多谷氨酸产 生 ${ }^{[1]}$. 其后我们发现日本血吸虫含有很强的
精氨酸酶 ${ }^{[2]}$. 由此推测在测定精氨酸的转氨 作用时，将同时发生精氨酸酶的反应，而所 产生的鸟氨酸也可能参与转氨作用 (图 1),

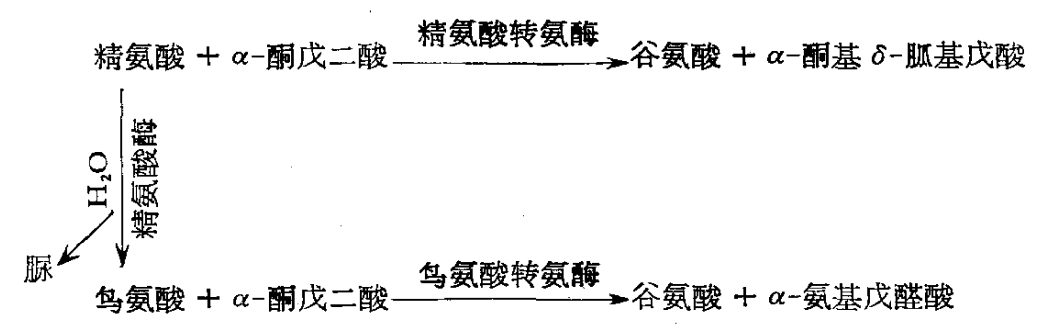

图 1 精氨酸酶与转氨酶的关系

因此我们对日本血吸虫的精氨酸转氨酶及鸟 氨酸转氨酶作了进一步的研究.

\section{精氨酸转氨酶的研究}

我们从以下三方面进行实验，观察日本 血吸虫的精氨酸转氨酶活力:

1. 用测定转氨酶的条件 ${ }^{[1]}$, 测定以精氨 酸为底物时的谷氨酸生成量, 并测定同时产 生的腿, 以估计参与转氨作用的鸟氨酸量. 反应系统中含 $\mathrm{L}-$ 精氨酸 50 微克分子， $\alpha$-酮 戊二酸 50 微克分子, 加入的血吸虫匀浆量 相当于合抱虫 20 对, 所用的缓冲液为 $\mathrm{pH} 7.4$
磷酸盐缓冲液，最后浓度 $0.1 \mathrm{M}$. 反应混合物 的总体积为 3.0 毫升. 实验结果生成的谷氨 酸为 1.80 微克分子, 腿为 5.62 微克分子. 另外, 用较低浓度的乌氨酸作底物进行乌氨 酸转氨酶活力的测定, 在上述的作用系统中 不加精氨酸而代之以 5 微克分子 L-乌氨酸, 结果生成的谷氨酸为 2.92 微克分子, 大于上 述以精氨酸为底物时的生成量.

2. 用嗍酸盐缓冲液代替磷酸盐缓冲液进 行与上述相同的实验。硼酸盐能部分地抑制 精氨酸酶, 但对乌氨酸转氨酶的活力无影响. 当以精氨酸为底物时, 随着嗍酸盐浓度的增 
高，脲和谷氨酸的生成量均逐渐降低，两者 的降低趋势几乎呈平行关系，脉的生成量始 终高于谷氨酸的生成量.

3. 以精氨酸或鸟氨酸为底物，按照测定 转氨酶的条件进行反应后测定生成的谷氨酸 和 $\alpha$-氨基戊醛酸 ${ }^{[3]}$ 的比值，以比较观察㨁接 从乌氨酸产生的谷氨酸量. 结果从两个反应 所测得的比值相等，表明当以精氨酸为底物 时，谷氨酸系来自精氨酸酶的产物乌氨酸。

以上实验表明，在本实验条件下不能测 出日本血吸虫中有精氨酸转氨酶的存在，而 乌氨酸转氨酶的活力则很強。

\section{鸟氨酸转袅酶的研究}

在 $37^{\circ} \mathrm{C} ， \mathrm{pH} 8.0 ， \mathrm{~L}$ 一鸟氨酸及 $\alpha$-酩戊二 酸的浓度各为 $0.017 \mathrm{M}$ 的条件下测定日本血 吸虫匀浆的转氨酶活力, 测定结果用微克分 子/毫克氮/小时表示，测得酶活力的平均值 雄虫为 33.9, 雌虫为 29.0 . 另用合抱虫在 $\mathrm{pH} 7.4$ 的条件下作鸟氨酸转氨酶与谷氨酸丙 酮酸转氨酶及谷氨酸草酰乙酸转氨酶的比较 测定，结果鸟氨酸转氨酶的活力为谷氨酸丙 酩酸转氨酶活力的 1.5 倍，谷氨酸草酰乙酸 转氨酶活力的 2.4 倍. 乌氨酸转氨酶的最适 $\mathrm{pH}$ 为 8.0 - 8.2 . 当用乌氨酸分別与 $\alpha$-酮戊 二酸、丙酮酸、草酰乙酸及乙醛酸进行反应 时, 测得酶活力的比值依次为 $100: 6.2: 1.8$ : 4.2. 磷酸吡哆醛 $\left(4 \times 10^{-5} M\right)$ 使酶活力增高
$18 \%$ 。硫氨腿 $\left(5 \times 10^{-3} M\right)$ ，异烟肼 $(5 \times$ $\left.10^{-3} M\right)$ 和差胺 $\left(5 \times 10^{-3} M\right)$ 分別使酶活力降 低 $30 \% 、 8 \%$ 和 $57 \%$ 。氯化铜及对氯录苯甲 酸具有很強的抑制作用，在 $2 \times 10^{-5} \mathrm{M}$ 浓度 下，前者抑制 $79 \%$ ，后者抑制 $32 \%$ 。 与乌 氨酸结构相似的捗氨酸和正捗氨酸显出颇強 的竞爭性抑制作用，当它们的浓度与底物乌 氨酸的浓度各为 $0.017 \mathrm{M}$ 时，前者抑制 酶 活 力 $22 \%$ ，后者抑制酶活力 $31 \%$ ，与此相反， 戊二酸及顺丁烯二酸在浓度为 $0.017 M$ 时， 仅对 $\alpha$-酮戊二酸 $(0.0017 M)$ 显出微弱的竞爭 性抑制作用．治疗血吸虫病的药物酒石酸銻 钾 $\left(10^{-3} M\right)$ 和呋喃丙胺 ${ }^{[4]}\left(10^{-4} M\right)$ 对酶活力无 影响，南瓜子氨酸 ${ }^{[5]}$ 在 $0.017 M$ 的浓 度下抑 制酶活力 $30 \%$ 。

从以上的实验结果可以看出, 日本血吸 虫除了含有很強的精氨酸酶之外，所含的乌 氨酸转氨酶的活力也很高, 由此可以推测精 氨酸和甶氨酸在血吸虫的代谢中可能起着重 要作用。

\section{参考 文献}

[1] Huang, T. Y., Tao, I. H. \& Chu, C. H., Chinese Med. I., 81, 79 (1962).

[ 2 ] Tao, I. H. \& Huang, T. Y., Scientia Sinica, 14, 417 (1965).

[3] Fincham, J. R. S., Biochem. J., 53, 313 (1953).

[4] Lei, H. H. et al., Chinese Med. J., 82, 90 (1963).

[5] Fang, S. D. et al., Scientia Sinica, 10, 845 (1961). 